\title{
CLASSIFICATION OF COMPANIES INTO STOCK EXCHANGE QUOTATION MARKETS USING NETWORK METRICS
}

The classification of a company into the relevant quotation market is an essential part of stock market efficiency. The aim of the article is to predict the classification of enterprises into the two types of quotation markets on the Warsaw Stock Exchange (i.e. the main one and NewConnect) by means of network measures of the company's participation in interlocking directorates' networks. The research was carried out on a network of enterprises established on the basis of their relationships through shared board directors. This network included 460 companies listed on the main exchange, and 442 companies in the NewConnect markets of the Warsaw Stock Exchange respectively (a total of 902 entities) at the end of 2014. The aim of the study is to classify the companies into the appropriate quotation market on the Warsaw Stock Exchange, i.e. the main market (WSE) or NewConnect (NC).

Keywords: classification, social network, interlocking directorates, network metrics JEL Classifications: G10, C45, C53

DOI: $10.15611 /$ aoe.2020.2.12

\section{INTRODUCTION}

The classification of a company to the relevant quotation market is an essential part of stock market efficiency. In addition to the formal requirements that the company must meet in order to be able to debut on the public markets - either the main (WSE) or NewConnect (NC), an important aspect should also be the relative comparability of the companies listed on the individual types of market.

The assets as well as the achievable market value of the company are the main factors differentiating the main Warsaw Stock Exchange (WSE) from NewConnect (NC). These categories are the key elements determining firm size. In addition to the size of the company, as measured by the value of the assets, an important criterion could be the company's participation in a network of companies. This may take the form of interlocking directorates, when one member of the company's board of directors also sits on the board

* Institute of Social Sciences and Management of Technologies, Lodz University of Technology 
of another company. In such a case there occurs an inter-organizational connection between the two firms (Mizruchi, 1996; Simoni, Caiazza, 2012; Bazerman, Schoorman, 1983; Pfeffer, Salancik, 2003/1978; ŚwiatowiecSzczepańska, Zdziarski, 2016). The company's participation in the network constitutes a non-classical factor for the economic efficiency of the enterprise, particularly in terms of creating its market value. Previous research shows that a company's position in the interlocking network structure determines its market value, measured by stock market capitalization and Tobin's Q ratio (Ferris et al., 2003; Durbach et al. 2013; Yeoet al. 2003; Hallock, 1997; Siudak, $2018 ; 2017)$. Both measures of the value of the company before the date of entry of the company on the stock market are only an estimate by valuation. On the other hand, the connections of the board of directors of the company planning to enter the stock market are known. Taking the position of this company in the structure of the board network may be an important element determining the classification to a given type of stock market (WSE vs. NC).

The aim of the article is to predict the classification of enterprises into the two types of quotation markets on the Stock Exchange (the main and NewConnect markets) by means of interlocking directorate network measures. As not all companies establish interlocking directorates networks, the classification must take into account the size of the company.

The hypothesis of this paper is that it is possible to effectively predict the classification of the company into the relevant quotation market by means of supervised learning algorithms based on economic and network variables, as a non-classical form of assessment of the efficiency of the classification process.

\section{RESEARCH METHOD}

In the study, two main research methods were used - (1) social network analysis (SNA) and (2) the classification method. Two network variables were defined with social network analysis. These are variables that determine the number of relationships for each vertex in the network and the company's position in the interlocking network. The specification of the variables is presented in the third part of the article. To solve the classification problem, a classification learning algorithm was applied which takes a dataset of variables as an input to infer classification rules. The algorithm generates a classifier that has the rules used to predict a classification. The process of classification was carried out using five algorithms of classification which fall into the category of supervised learning algorithms: 1) naive Bayes;

2) discriminant analysis; 3) multilayer perceptron. 4) support vector machine - SVMs; 5) classification and regression tree-CART. A detailed description 
of the algorithms can be found in the work by (Murphy, 2012; Flach, 2015; Kelleher et al. 2015; Mitchell, 1997; Demsar, 2006). In the classification method the prevailing belief is that there exists no single algorithm that will generate better classification results for every type of data. The methodological basis of the listed classification algorithms is founded on various assumptions and characteristics. However, a consistent empirical structure is preserved in the study. In the problems of classification tasks, the quality of classification reflected in real data is important. The classification of companies into the appropriate stock exchange market should be considered appropriate in a situation where the misclassification rate is as low as possible and classification accuracy is the highest. Since the aim was to obtain the classification best suited to the actual data for the research purpose of the work, the approach adopted in applying different classification methods is justified. Hence, it was necessary to select the optimal algorithm on the basis of the basic classification assessment measures. In the study, it was possible to select the best-fitting algorithm classifying a company into the appropriate quotation market. It should be noted that the classification algorithm indicated in the paper applies only to the analyzed subject. Since the aim of the paper is not to indicate the best overall classification method, in other applications the best results can be achieved using another classification method. It should be pointed out that the range of differences in the size of the basic measures of the results of classification of enterprises into the relevant stock market using different methods indicates the degree of dependence of the classification result on the type of method. In a later part of this paper, an extended analysis of the results of the classification matches is presented.

For the supervised learning algorithms used for the purpose of classification, the original research sample is divided into two sets of data - the training set and the test set. This is an important element of the design for the evaluation of research results for predictive models, and, at the same time, an implementation of the basic principle stating that the evaluation should not take place on the exact same data as the learning process of the system. In other words, the training set is used for teaching the model, while the test set - to evaluate the quality of the classification.

The basis for the assessment of the correctness of the classification is a contingency matrix, consisting of the incidence of various possible outcomes predicted by the model based on a set of test data. For binary models in which there are only two targets, where they are referred to as positive/negative ${ }^{1}$

\footnotetext{
1 The naming of these stems from the methods often used in medicine to predict the incidence of patients for a disease based on specified symptoms.
} 
respectively, the matrix size is $2 \times 2$, which is presented in Table 1 , where: TP (true positive) - correctly classified positives; TN (true negative) - correctly classified negatives; FP (false positive) - incorrectly classified positives ${ }^{2}$; FN (false negative) - incorrectly classified negatives ${ }^{3}$.

Table 1

The structure of a confusion matrix

\begin{tabular}{c|l|c|c}
\hline \multirow{2}{*}{ Levels } & \multicolumn{2}{c}{ Predicted } \\
\cline { 2 - 4 } & \multicolumn{1}{|c|}{ Type } & positive & negative \\
\hline \multirow{2}{*}{ Original } & positive & TP & FN \\
\cline { 2 - 4 } & negative & FP & TN \\
\hline
\end{tabular}

Source: Kelleher, Mac Namee, D’Arcy (2015).

On the basis of a contingency matrix, the following characteristics can be calculated (Kelleher et al 2015):

1) Misclassification rate

$$
\text { Misclassification rate }=\frac{(F P+F N)}{(T P+T N+F P+F N)},
$$

2) Classification accurate

$$
\begin{gathered}
\text { Classification accurate }=\frac{(T P+T N)}{(T P+T N+F P+F N)}= \\
=(1-\text { Misclassification rate })
\end{gathered}
$$

3) Precision

$$
\text { Precision }=\frac{T P}{(T P+F P)} \text {, }
$$

4) Recall, equivalently TPR - true positive rate

$$
\text { Recall }=T P R=\frac{T P}{(T P+F N)},
$$

2 The so-called Type I error'

3 The so-called Type II error. 
5) FPR - false positive rate

$$
F P R=\frac{F P}{(T N+F P)},
$$

6) $F_{1}$ measure

$$
F_{1}=2 \times \frac{(\text { precision } \times \text { recall })}{(\text { precision }+ \text { recall })} .
$$

7) ROC index (receiver operating characteristic index), also referred to as the area under the ROC curve - AUC

ROC index $=$

$$
=\sum_{i=2}^{|T|} \frac{(F P R(\boldsymbol{T}[i])-F P R(\boldsymbol{T}[i-1])) \times(T P R(\boldsymbol{T}[i])-T P R(\boldsymbol{T}[i-1]))}{2},
$$

where: $\mathbf{T}$ - is a set of thresholds in the range $[0,1] ;|\mathbf{T}|-$ number of thresholds tested; $\mathbf{T}[i]$ - threshold $i$.

8) Gini coefficient

$$
\text { Gini coefficient }=(2 \times \text { ROC index })-1 .
$$

The measures (1)-(5) and (7), (8) are within the $[0,1]$ scope, while $F_{1}$ measure (6) is within the $(0,1]$ scope. The greater the values of the measures (2), (3), (4), (6), (7), (8), and the smaller the values of the measures (1), (5), the better the evaluation of the predictive model.

\section{RESEARCH DESIGN}

The study was carried out on an undirected network of enterprises established on the basis of their relationship through the boards of directors. Whenever two companies share a director in the affiliation network (a twomode network), there is a link between them in the one-mode network. Board interlocking networks derived from a two-mode network can be analysed with standard techniques of a social network analysis. The network included 460 companies listed on the main market of Warsaw Stock Exchange (SWE) and the 442 companies listed on the NewConnect market (NC), a total of 902 entities at the end of 2014. Since the subject of the study was a network in the informational sense, where connections enable a flow of information, for the purpose of the study it was assumed that the boards of directors included 
members of the management boards and the supervisory boards collectively (a total of 5,928 people). The information about the people sitting on the boards of directors, as well as the economic data, was obtained from the Notoria service, as of 31 December 2014 (the preparation of financial statements). Due to missing data, the number of companies in the sample was finally reduced to 855 firms.

The original total research sample was of considerable size (855), which was divided in a proportion of $80 \%$ for the training set (684) and $20 \%$ for the test set (171). The division process was random, performed on non-repeating elements, subject to the proportionality of the sampling method, and consisted in maintaining a consistent distribution of variables subjects assigned to the test set as compared with the distribution for the whole of the original sample.

The classification was carried out on the basis of a two-valued variable, i.e. Market $(0,1)$, where value 0 means that the company is listed on the NewConnect market (NC), and value 1 for the main market of the Warsaw Stock Exchange (WSE),

$$
\begin{aligned}
& \text { Market }(0,1)= \\
& = \begin{cases}1 ; & \text { when the company is listed on the the Warsaw Stock Exchange } \\
0 ; & \text { when the company is listed on the NewConnect market }\end{cases}
\end{aligned}
$$

In the process of classifying the enterprise to the appropriate quotation market, the following three variables were used, where variables 2 and 3 are network variables.

1) The natural logarithm of the assets - $\ln$ (Assets), which is a measure of the firm size that determines its financial performance. Economic data about company assets come from the preparation of financial statements. Companies with a higher market value, calculated in terms of stock market capitalization, usually have a higher value of assets, and thus have a higher book value of assets. The size of a company, determined by the logarithm of the natural value of assets, may be an appropriate economic measure to classify the division into a type of stock market.

2) Degree -the number of links with other companies in an interlocking network. The degree of a vertex is equal to the number of edges connected to it if the network is undirected, unweighted and without self-loops.

$$
d_{i}=\sum_{j=1}^{N} a_{i j} \text { for } i \neq j
$$

where: $d_{i}$ - degree of vertex $i, N$ - number of vertices in the network, $a_{i j}$ - elements of the adjacency matrix $\mathbf{A}$, where: 


$$
a_{i j}= \begin{cases}1 ; & \text { if there is an link between vertices } i \text { and } j \\ 0 ; & \text { otherwise }\end{cases}
$$

Freeman (1978) indicated that the degree is simple and measured by the number of direct ties involving a node in a network. The degree is the basic measure of assessment of involvement in the interlocking directorates network. A larger number of relationships in the network characterizes larger enterprises employing outside directors from other companies listed on the stock exchange. On the other hand, the NewConnect market lists family businesses that avoid engaging outside directors in the board of directors. Thus, these are isolated companies with a degree of 0 .

3) Polytomous variable - Component $(0,1,2)$ - a measurement of the company's position in the interlocking network

Component $(0,1,2)=$

$$
=\left\{\begin{array}{l}
0 ; \text { the company is isolated }(\text { degree }=0) \\
1 ; \text { the company is located outside the largest component and degree } \geq 1 \\
2 ; \text { the company is located inside the largest component and degree } \geq 1
\end{array} .\right.
$$

A variable constructed in this way determines the application by a company of an interlocking strategy in connection with its position in the network, on the basis of information about the degree and whether the company is part of the largest component of the network. In an undirected and social network there is a large component that contain more than a half of the network. The rest of the network is divided into a large number of small components and isolated nodes. A component is a subset of the nodes of a network such that there exists at least one path between each vertex of that subset (Newman, 2010). Based on information about the degree and composition of the largest component, one can assign each firm to one of three states: 1) isolation, where the variable assumes a value of 0 if the company does not apply an interlocking strategy and degree $=0 ; 2$ ) networking outside the largest component, where the variable assumes a value of 1 if the company applies an interlocking strategy (degree $>0$ ) but the company is outside the largest component; 3) networking inside the largest component, where the variable assumes a value of 2 if the company applies an interlocking strategy (degree $>0$ ) and at the same time is located in the largest network component.

The effect of the degree in the interlocking directorates network on the value of the company partly ignores the aspect of whether the enterprise is part of the largest component of the network or whether these relationships do not provide a link with the largest component of the network. Based on the 
network degree measure, it can only be determined whether the enterprise is isolated or has relations in the network, although without information whether it is part of the largest network component. This effect was taken into account in (Siudak, 2017, 2018). Based on the analysis of variance (ANOVA), enterprises belonging to the largest network component have a significantly higher statistical market value than organizations that are outside the largest network component, but are not isolated in the network (Siudak, 2017). At the same time, it was shown on the basis of regression analysis that networking within the largest network component results in a higher market value of the enterprise (Siudak, 2018). Companies with a higher market value should be classified on the main market (WSE), and enterprises with a lower market value on the $\mathrm{NC}$ market.

Table 2

Descriptive statistics

\begin{tabular}{l|l|c|c|c|c|c|c|c|c}
\hline $\begin{array}{c}\text { Grouping } \\
\text { variable }\end{array}$ & \multicolumn{1}{|c|}{ Variable } & $N$ & Mean & $\begin{array}{c}\text { Std. } \\
\text { dev. }\end{array}$ & $\begin{array}{c}\text { Mean } \\
\text { error }\end{array}$ & Min. & Median & Max. & $\begin{array}{c}\text { Coefficient } \\
\text { of variation }\end{array}$ \\
\hline \multirow{2}{*}{$\begin{array}{l}\text { The whole } \\
\text { network }\end{array}$} & $\ln$ (Assets) & 855 & 10,840 & 2,428 & 0,083 & 4,104 & 10,757 & 19,803 & 22,400 \\
\cline { 2 - 10 } & Degree & 855 & 2,856 & 3,343 & 0,114 & 0,000 & 2,000 & 19,000 & 117,042 \\
\cline { 2 - 10 } & Component $(0,1,2)$ & 855 & 1,290 & 0,888 & 0,030 & 0,000 & 2,000 & 2,000 & 68,867 \\
\hline \multirow{2}{*}{ WSE } & $\ln$ (Assets) & 436 & 12,544 & 1,920 & 0,092 & 4,649 & 12,240 & 19,803 & 15,303 \\
\cline { 2 - 10 } & Degree & 436 & 3,305 & 3,459 & 0,166 & 0,000 & 2,000 & 19,000 & 104,656 \\
\cline { 2 - 10 } & Component $(0,1,2)$ & 436 & 1,452 & 0,830 & 0,040 & 0,000 & 2,000 & 2,000 & 57,199 \\
\hline \multirow{2}{*}{ NC } & $\ln$ (Assets) & 419 & 9,067 & 1,424 & 0,070 & 4,104 & 9,055 & 14,482 & 15,708 \\
\cline { 2 - 10 } & Degree & 419 & 2,389 & 3,155 & 0,154 & 0,000 & 1,000 & 19,000 & 132,044 \\
\cline { 2 - 9 } & Component $(0,1,2)$ & 419 & 1,122 & 0,916 & 0,045 & 0,000 & 1,000 & 2,000 & 81,668 \\
\hline
\end{tabular}

Source: own elaboration based on empirical research.

The analyses, both in terms of social networks and the supervised learning algorithms, were carried out using the NetMiner 4 software (Cyram, 2020). The descriptive statistics of the variables are presented in Table 2.

\section{EVALUATION OF THE CLASSIFICATION RESULTS}

The parameters for the algorithms used are presented in appendix A. Table 3 illustrates the basic classification evaluation measures - classification accurate (2) and misclassification rate (1). The lowest value of misclassification rate $(9.94 \%)$ and the highest classification accuracy $(90.06 \%)$ were obtained for the multilayer perceptron algorithm. This means that of the 171 cases, 
9.94\% had been classified wrongly, and $90.06 \%$ - correctly. It should be noted that no method of classification offers $100 \%$ accuracy of prediction. At the same time, this algorithm scored the highest value of Cohen's kappa coefficient -0.801 , the Cohen's kappa measure of inter-annotator agreement to measure how closely the manual classifications matched each other (Kelleher et al. 2015, p. 509). Consequently, it was concluded that the multilayer perceptron algorithm generated the best results, and it is for this classification that an assessment is presented later in this paper.

\section{Table 3}

Basic classification results using various algorithms

\begin{tabular}{l|c|c|c}
\hline $\begin{array}{c}\text { Classification } \\
\text { algorithm }\end{array}$ & $\begin{array}{c}\text { Classification } \\
\text { accurate }\end{array}$ & $\begin{array}{c}\text { Misclassification } \\
\text { rate }\end{array}$ & $\begin{array}{c}\text { Cohen's kappa } \\
\text { coefficient }\end{array}$ \\
\hline Naive Bayes & $84.21 \%$ & $15.79 \%$ & 0.685 \\
\hline Discriminant analysis & $88.30 \%$ & $11.70 \%$ & 0.767 \\
\hline Multilayer perceptron & $90.06 \%$ & $9.94 \%$ & 0.801 \\
\hline SVMs & $88.30 \%$ & $11.70 \%$ & 0.767 \\
\hline CART & $85.96 \%$ & $14.04 \%$ & 0.720 \\
\hline
\end{tabular}

Note: $\mathrm{n}=171$

Source: own elaboration based on empirical research.

Despite different assumptions of the methodology of classification of particular algorithms, the basic results of classification of companies are similar to the appropriate exchange market. A classification accurate for five division methods is in the range from $84.21 \%$ to $90.06 \%$ and misclassification rate from $9.94 \%$ to $15.79 \%$. The worst result obtained using naive Bayes, where over $84 \%$ of cases had been classified correctly, is satisfactory in terms of classification correctness. Moreover, two algorithms - discriminant analysis and SVMs - achieved exactly the same level of basic classification measures. This indicates the relative resilience of the classification methods used in the adopted test area.

Table 4 shows the confusion table drawn up on the basis of the classification of companies to the quotation market type by means of the multilayer perceptron algorithm. Out of 87 companies listed on the main capital market (WSE), 11 were wrongly classified to the NC market. On the other hand, out of 84 companies listed on the NC market, only six were incorrectly classified into the main market (WSE). 
Table 4

A confusion table for the test set

\begin{tabular}{l|c|c}
\hline Original & Predicted & NC \\
\hline WSE & 76 & 11 \\
\hline NC & 6 & 78 \\
\hline
\end{tabular}

Note: $\mathrm{n}=171$

Source: own elaboration based on empirical research.

Table 5 shows the more accurate results of the evaluation. The values of TP, FP, TN and FN were taken from the contingency table (Table 2). Based on those values, the measures (3), (4), (6)-(8) were calculated for the appropriate target levels (possible markets WSE or NC).

Table 5

Analysis of the accuracy of the anticipated classes

\begin{tabular}{l|c|c|c|c|c|c|c|c|c}
\hline $\begin{array}{c}\text { Quotation } \\
\text { market }\end{array}$ & TP & FP & TN & FN & $\begin{array}{c}\text { Precision TP/ } \\
(\mathrm{TP}+\mathrm{FP})\end{array}$ & $\begin{array}{c}\text { Recall TP/ } \\
(\mathrm{TP}+\mathrm{FP})\end{array}$ & $\begin{array}{c}\mathrm{F}_{1} \\
\text { measure }\end{array}$ & $\begin{array}{c}\text { ROC } \\
\text { index }\end{array}$ & $\begin{array}{c}\text { Gini } \\
\text { coefficient }\end{array}$ \\
\hline WSE & 76 & 6 & 78 & 11 & 0.9268 & 0.8736 & 0.8994 & 0.9507 & 0.901 \\
\hline NC & 78 & 11 & 76 & 6 & 0.8764 & 0.9286 & 0.9017 & 0.9615 & 0.923 \\
\hline \multicolumn{7}{l}{ Weighted average } \\
\hline
\end{tabular}

Note: $\mathrm{n}=171$

Source: own elaboration based on empirical research.

For the main market (WSE), the value of precision was 0.9268 and for $\mathrm{NC}$ 0.8764 . This means that the model made accurate predictions in $92.68 \%$ $(87.64 \%)$ cases. The weighted average of the number of cases actually classified into a given category is $90.21 \%$.

Recall indicates the share of cases at the target level, which are predicted by the model. In other words, of all the companies of the WSE (NC) target category, the model correctly predicts the classifications in $87.36 \%(92.86 \%)$ of cases. The weighted average is $90.06 \%$.

The $F_{1}$ measure combines the measures of precision and recall through harmonic mean. The values obtained were close to 0.9 , which testified to the high evaluation of the expected classification.

The classification carried out with the multilayer perceptron algorithm received a very high value of ROC index. In probabilistic terms, the ROC 


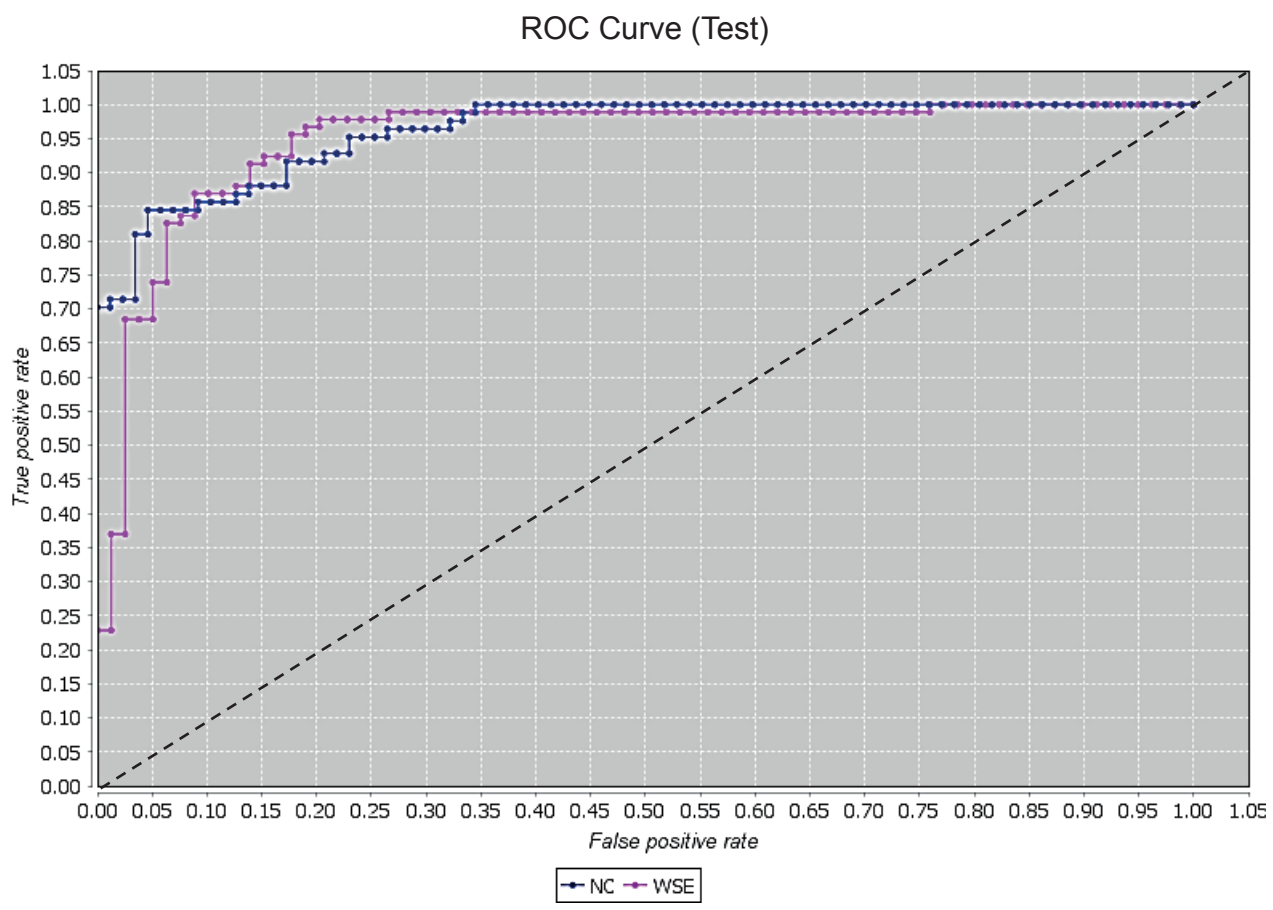

Fig. 1. The ROC curve for test set

Source: own elaboration based on empirical research.

index means the probability that the model sets a higher rank for randomly selected cases with positive target levels than to randomly chosen cases with negative target levels. The value of the ROC index below the level of 0.6 means that the model is weak, and the value above 0.7 - that it is strong (Kelleher, Mac Nam+ee, D'Arcy, 2015)4. The higher the value, the better the evaluation. The weighted average was 0.9561 , and the average value of the Gini coefficient, as a linear transformation of the ROC index, was 0.912.

The ROC index measures the area under the ROC curve (Hand, Anagnostopoulos, 2013), drawn up on the basis of the value of TPR (recall) and the FPR (on the axis of ordinates and axis abscissae, respectively) for individual thresholds. Due to the higher the recall (TPR) and the lower value of the FPR, the model can only perfectly predict classifications to the category at the point of the upper-left corner of the space in the coordinate system. Thus, the model gets a better assessment of its predictive capacity if the course

${ }^{4}$ The value below 0.5 is unlikely and it means error of the classifier. 
of the ROC curve is similar to the upper-left corner of the coordinate system, and consequently, if the area under the ROC curve, the ROC index value and the Gini coefficient are also bigger. The course of the ROC curve for two categories (the WSE and NC) is presented in Figure 1. The dashed line means the reference line that indicates the expected result of classification based on random prediction. The profile of the course of the ROC curve confirms the conclusions obtained from the analysis of the ROC index. It should be noted that the ROC curve for $\mathrm{NC}$ is slightly greater than for the primary trading market (WSE), which confirms the greater share of correct classification for the target companies listed on the NC market compared to the Warsaw Stock Exchange (the ROC index for NC is 0.9615 vs. 0.9507 for WSE).

Table 6 presents the statistics of a Z-test for the actual classification error rate obtained by testing the hypothesis that the misclassification rate is less than $15 \%$. The Z-test statistic is at the level of $\alpha<0.05$, indicating that the misclassification rate is significantly lower than the threshold of $15 \%$.

Table 6

Hypothesis test of misclassification rate

\begin{tabular}{c|c|c|c}
\hline Error rate $<\mathrm{p}_{0}$ & $\begin{array}{c}\mathrm{p}_{1} \\
\text { (misclassification rate) }\end{array}$ & $\mathrm{Z}$ & p-value (one-sided) \\
\hline $15 \%$ & $9.94 \%$ & -1.8525 & 0.032 \\
\hline
\end{tabular}

Note: $\mathrm{n}=171$

Source: own elaboration based on empirical research.

Table 7

Measures for classification assessment for the training and test sets the multilayer perceptron algorithm

\begin{tabular}{l|c|c}
\hline \multicolumn{1}{c|}{ Measure } & training set & test set \\
\hline$N$ & 684 & 171 \\
\hline classification accurate & $87.87 \%$ & $90.06 \%$ \\
\hline misclassification rate & $12.13 \%$ & $9.94 \%$ \\
\hline Cohen's kappa coefficient & 0.7571 & 0.8013 \\
\hline precision $^{*}$ & 0.8787 & 0.9021 \\
\hline recall $^{*}$ & 0.8787 & 0.9006 \\
\hline$F_{1}$ measure $^{*}$ & 0.8786 & 0.9006 \\
\hline ROC index & 0.9479 & 0.9561 \\
\hline Gini coefficient $^{*}$ & 0.8958 & 0.9122 \\
\hline
\end{tabular}

Note: * - weighted average.

Source: own elaboration based on empirical research. 
In evaluating the predictive capability, it is important to obtain better classification assessment rates for the test set than for the training set. This condition was met for the classification of companies to the relevant quotation market. Table 7 presents the results.

Table 8 contains the discriminatory function parameters for the classification (Fisher, 1936; 1925/1995) obtained with a discriminant analysis algorithm, where the level of classification error, at $11.7 \%$, scored second best (with $9.94 \%$ as the best result).

Table 8

Discriminant function table for the discriminant analysis algorithm

\begin{tabular}{l|c}
\hline \multicolumn{1}{c|}{ Variable } & WSE $<>$ NC \\
\hline Constant & -13.035 \\
\hline Degree & 0.081 \\
\hline Component $(0,1,2)$ & 0.133 \\
\hline $\ln$ (Assets) & 1.165 \\
\hline
\end{tabular}

Note: $\mathrm{n}=171$

Source: own elaboration based on empirical research.

The largest parameter in the discriminatory function was obtained for the variable $\ln$ (Assets), which is associated with the size of the enterprise. Of less importance for the classification were the variables Degree and the Component $(0,1,2)$. Taking into account that network variables are classified as non-classical factors of company efficiency, their participation in a discriminatory feature, especially for the variable Component $(0,1,2)$, is significant for predicting the classification of companies to the appropriate quotation market.

Confirmation of the greater influence of company size measured by the natural logarithm of assets compared to network variables on the type of stock market are surface charts presented in Figures $2 b$ and $2 c$. The network factor has a much smaller impact. However, the influence on the type of stock market of Degree and Component $(0,1,2)$ variables is noticeable - see Figure 2a. For larger degree values and if the company is located in the largest network component, the WSE is a more prevalent stock market.

The assessment of the impact of network variables on the quality of classification using all five algorithms was carried out on the basis of comparison of model classification results excluding network variables, taking into account only the $\ln$ (Assets) variable. Table 9 shows the basic classification results for the model without network variables, where the results for the basic model are repeated in brackets (see Table 3). 

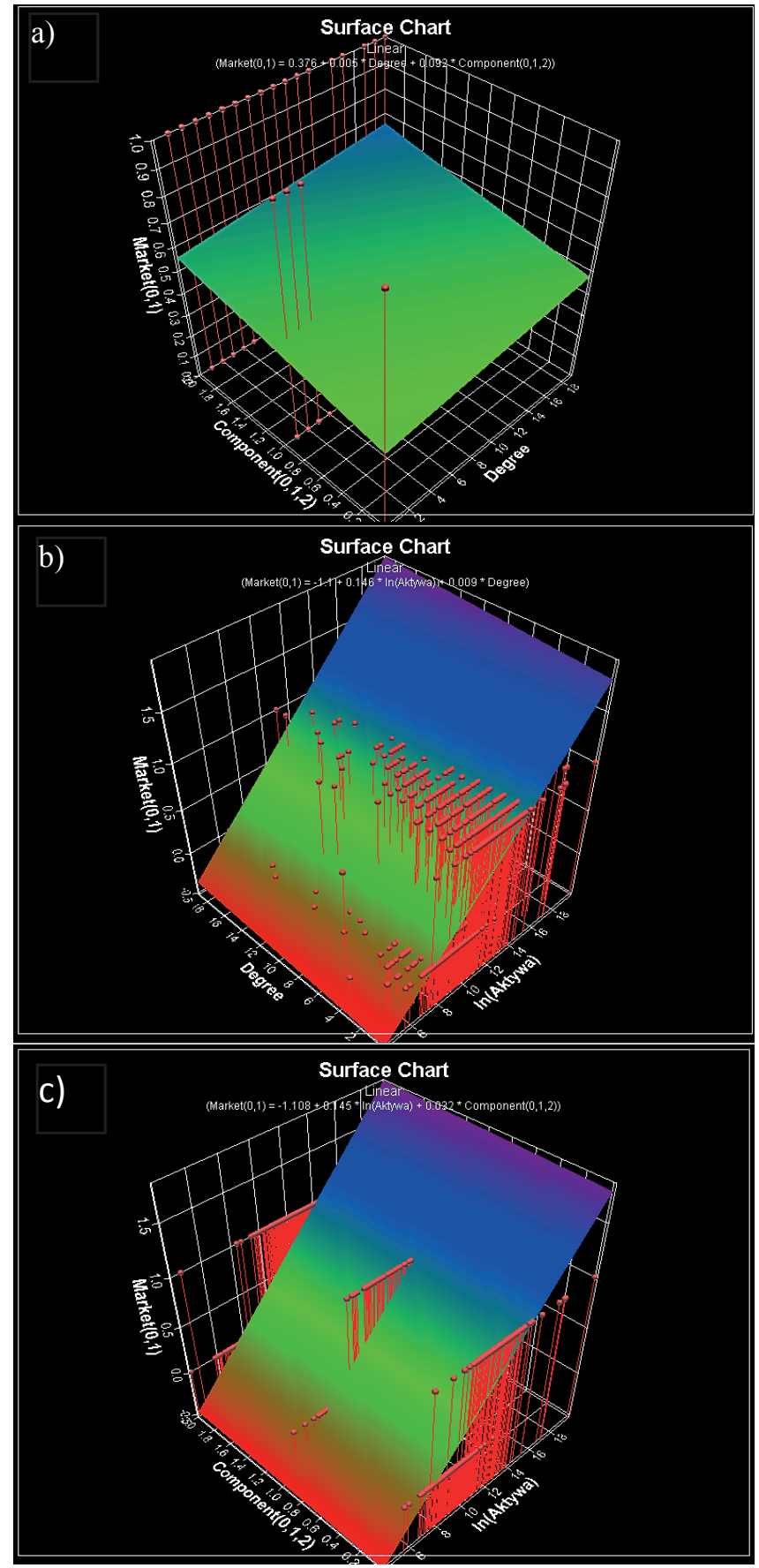

Fig. 2. Surface chart for the Market variable relative to a) network variables; b) $\ln$ (Assets) and Degree; c) $\ln$ (Assets) and Component $(0,1,2)$

Source: own elaboration based on empirical research. 
Table 9

Basic classification results for the model without network variables

\begin{tabular}{l|c|c|c|c}
\hline $\begin{array}{c}\text { Classification } \\
\text { algorithm }\end{array}$ & $\begin{array}{c}\text { Classification } \\
\text { accurate }\end{array}$ & $\begin{array}{c}\text { Misclassification } \\
\text { rate }\end{array}$ & $\begin{array}{c}\text { Cohen's } \\
\text { kappa } \\
\text { coefficient }\end{array}$ & $\begin{array}{c}\text { Difference } \\
\text { misclassification rate } \\
\text { to the basic model } \\
\text { (percentage points) }\end{array}$ \\
\hline Naive Bayes & $\begin{array}{c}82.46 \% \\
(84.21 \%)\end{array}$ & $\begin{array}{c}17.54 \% \\
(15.79 \%)\end{array}$ & $\begin{array}{c}0.647 \\
(0.685)\end{array}$ & -1.75 \\
\hline $\begin{array}{l}\text { Discriminant } \\
\text { analysis }\end{array}$ & $\begin{array}{c}87.13 \% \\
(88.30 \%)\end{array}$ & $\begin{array}{c}12.87 \% \\
(11.70 \%)\end{array}$ & $\begin{array}{c}0.743 \\
(0.767)\end{array}$ & -1.17 \\
\hline Multilayer & $88.89 \%$ & $11.11 \%$ & 0.778 & -1.17 \\
perceptron & $(90.06 \%)$ & $(9.94 \%)$ & $(0.801)$ & -6.43 \\
\hline SVMs & $81.87 \%$ & $18.13 \%$ & 0.635 & -1.75 \\
\hline CART & $(88.30 \%)$ & $(11.70 \%)$ & $(0.767)$ & $\begin{array}{c}0.685 \\
(84.21 \%\end{array}$ \\
\hline
\end{tabular}

Note: value in parentheses for the basic model; $\mathrm{n}=171$

Source: own elaboration based on empirical research.

The difference between models for the misclassification rate ranges from -6.43 (for SVMs) to - 1.17 (for multilayer perceptron and discriminant analysis) percentage points to the detriment of the model excluding network variables. In other words, the inclusion of network variables that determine the number of relationships and the position of an enterprise in an interlocking network improves the classification results.

\section{CONCLUSION}

This study attempted to predict the classification of enterprises into the two types of quotation markets on the Warsaw Stock Exchange (i.e. WSE and NewConnect). On the basis of economic variables (Assets) and network variables for company networks - interlocking directorates - the achieved result was satisfactory. However, the differences in the classification results obtained using five algorithms are not significant. For the defined purpose of the work, which is the proper division of enterprises into the type of stock exchange market, the multilayer perceptron algorithm proved to be the most effective in this regard, with the error of the predictive model amounted to less 
than $10 \%$, and ROC index 0.956 . In addition, network variables have the effect of improving the classification.

It should be noted that after a certain period of quotations, some companies will be required to change the quotation market due to revised requirements. In this respect, the model turns out to be a good predictor of the classification of a company to the appropriate quotation market. The model can be applied for the classification of companies applying for their stock market debut in cases when the company meets the formal requirements for listing on both markets.

At the same time, the method used for predicting the classification, i.e. the supervised learning algorithm, can be adapted to solve many different kinds of economic research problems.

\section{REFERENCES}

Bazerman, M., Schoorman, F., A Limited Rationality Model of Interlocking Directorates, "Academy of Management Review", 8, pp. 206-217, 1983.

Cyram, NetMinerVersion: 4.4.3.e, Cyram Inc., Seoul, 2020.

Demsar, J., Statistical Comparison of Classifier over Multiple Data Set, "Journal of Machine Learning Research”, 7, pp. 1-30, 2006.

Durbach, I., Katshunga, D., Parker, H., Community Structure and Centrality Effects in the South African Company Network, "South African Journal of Business Management", 44, pp. 35-43, 2013.

Ferris, S., Jagannathan, M., Pritchard, A., Too Busy to Mind the Business? Monitoring by Directors with Multiple Board Appointments, "The Journal of Finance", 58, pp. 1087-1111, 2003.

Fisher, R. A., Statistical Methods, Experimental Design, and Scientific Inference. Oxford University Press, 1925/1995.

Fisher, R. A., The Use of Multiple Measurements in Taxonomic Problems, "Annals of Eugenics", vol. 7, pp. 179-188, 1936.

Flach, P., Machine Learning. The Art and Science of Algorithms that Make Sense of Data. Cambridge University Press, 2015.

Freeman, L., Centrality in Social Networks Conceptual Clarification, "Social Networks", 1(3), pp. 215-239, 1978.

Hallock, K., Reciprocally Interlocking Boards of Directors and Executive Compensation, "Journal of Financial and Quantitative Analysis", 32, pp. 332-344, 1997.

Hand, D., Anagnostopoulos, C., When is the Area under the Receiver Operating Characteristic Curve an Appropriate Measure of Classifier Performance?, "Pattern Recognition Letters", 34(5), pp. 492-495, 2013.

Kelleher, J., Mac Namee, B., D’Arcy, A., Fundamentals of Machine Learning for Predictive Data Analytics. Algorithms, Worked Examples, and Case Study. The MIT Press, Cambridge, Massachusetts, 2015. 
Mitchell, T., Machine Learning. McGraw-Hill Science, 1997.

Mizruchi, M., What do Interlocks do? An Analysis, Critique, and Assessment of Research on Interlocking Directorates, “Annual Review of Sociology”, 22, pp. 271-298, 1996.

Murphy, K., Machine Learning. A Probabilistic Perspective. The MIT Press, Cambridge, Massachusetts, 2012.

Newman, M., Networks. An Introduction. Oxford University Press, 2010.

Pfeffer, J., Salancik, G., The External Control of Organizations: A Resources Dependence Perspective. Stanford University Press, Stanford. 2003/1978.

Simoni, M., Caiazza, R., Interlocks Network Structure as Driving Force of Coopetition among Italian Firms, "Corporate Governance", 12, pp. 319-336, 2012.

Siudak, D., Strategia interlocking directorates a wartość przedsiębiorstwa [Interlocking directorates strategy vs. corporate value], "Nauki o Finansach", 1(30), pp. 76-85, 2017.

Siudak, D., Analiza dynamiczna wptywu usieciowienia na wartość przedsiębiorstwa [Dynamic Analysis of the Impact of Network Relationships on the Company Value]. PWN, 2018.

Światowiec-Szczepańska, J., Zdziarski, M., Position in Corporate Network, Performance and Strategic Risks, "Problemy Zarządzania", Vol. 14, Issue 4 (64), pp. 157-176. 2016.

Yeo, H., Pochet, C., Alcouffe, A., CEO Reciprocal Interlocks in French Corporations, “Journal of Management and Governance", 7, pp. 87-108, 2003.

Received: December 2018, revised: February 2020

Acknowledgement: This research was supported by a grant financed by the National Science Center based on decision no. DEC-2013/11/B/HS4/00466. 


\section{APPENDIX A}

Parameters for the classification algorithms

\begin{tabular}{|c|c|}
\hline $\begin{array}{l}\text { Classification } \\
\text { algorithm }\end{array}$ & Parameters \\
\hline Naive Bayes & $\begin{array}{l}\text { Split test set: random, proportion: } 20.0 \% \\
\text { Sampling method: Stratified (proportional) } \\
\text { Prior policy: Empirical (the prior probabilities are assigned from the } \\
\text { distribution of the node's labels in a training set) }\end{array}$ \\
\hline $\begin{array}{l}\text { Discriminant } \\
\text { analysis }\end{array}$ & $\begin{array}{l}\text { Split test set: random, proportion: } 20.0 \% \\
\text { Sampling method: Stratified (proportional) } \\
\text { Covariance policy: Linear (nodes for each label share a common estimate of } \\
\text { covariance) } \\
\text { Prior policy: Empirical (the prior probabilities are assigned from the } \\
\text { distribution of the node's labels in a training set) }\end{array}$ \\
\hline $\begin{array}{l}\text { Multilayer } \\
\text { perceptron }\end{array}$ & $\begin{array}{l}\text { Split test set: random, proportion: } 20.0 \% \\
\text { Sampling method: stratified (proportional) } \\
\text { Hidden layers: } 1 \\
\text { Number of neurons: } 10 \\
\text { Activation function: } \operatorname{ReLU}: \max (0, \mathrm{x}) \\
\text { Learning rate: } 0.05 \\
\text { Maximum epochs: } 1000 \\
\text { Accuracy: } 0.0001\end{array}$ \\
\hline SVMs & $\begin{array}{l}\text { Split test set: random, proportion: } 20.0 \% \\
\text { Sampling method: stratified (proportional) } \\
\text { Kernel functions : quadratic } \\
\text { Maximum iteration : } 15000 \\
\text { KKT tolerance (a tolerance for convergence) }: 0.001 \\
\text { KKT violation level : } 0.0 \text { (none of the nodes can violation the Kraush-Kuhn- } \\
\text { Tucker conditions) } \\
\text { Box constraint : } 1.0 \text { (box constraint for the soft margin) }\end{array}$ \\
\hline CART & $\begin{array}{l}\text { Split test set: random, proportion: } 20.0 \% \\
\text { Sampling method: stratified (proportional) } \\
\text { Minimum leaf size : } 1 \\
\text { Minimum node size to be split : } 85 \\
\text { Criterion: entropy } \\
\text { Pruning : yes (reshapes the full tree to prevent overfitting) }\end{array}$ \\
\hline
\end{tabular}

Source: own elaboration. 